Review

\title{
Addressing Symptom Clusters with Complementary and Integrative Health Therapies in Palliative Care Populations: A Narrative Review.
}

Lucille Marchand ${ }^{1,}{ }^{*}$, Donna Lewin ${ }^{1}$, Leila Kozak ${ }^{1,2}$

1. University of Washington, 1959 NE Pacific St., Seattle, WA, United States; E-Mails: Irm19@uw.edu; lewind@uw.edu; lkozak@integrativepalliativecare.org

2. Integrative Palliative Care Institute (IPCI), 7345 164th Ave NE, Suite 145-168, Redmond WA, United States

* Correspondence: Lucille Marchand; E-Mail: Irm19@uw.edu

Academic Issue Editor: Gerhard Litscher

Special Issue: Integrative Therapies in Palliative Care

OBM Integrative and Complementary Medicine Received: October 02, 2020

2021, volume 6, issue 1

Accepted: February 02, 2021

doi:10.21926/obm.icm.2101007

Published: February 22, 2021

\begin{abstract}
Both palliative care (PC) and integrative medicine (IM) focus on the whole person to optimize wellbeing. Integrative palliative care combines the best of both approaches in relieving the distressing symptoms of serious illness and its treatment by combining evidence informed, pharmacological and nonpharmacological modalities that are aligned with the person's goals, values and preferences. Healing is valued, as well as symptom relief, shared decisionmaking, person empowerment, compassionate care, and nurturing of hope. Increasingly, symptom clusters in serious illness are being recognized and addressed in both PC and IM. Symptom clusters arise from the complexity of the physical, psychological, social and spiritual aspects of a person interacting with serious illness. Many complementary and integrative health $(\mathrm{ClH})$ modalities address symptom clusters effectively, and may allow for reduced doses of medication and their resulting side effects, or help alleviate the need for medication altogether, and increase
\end{abstract}

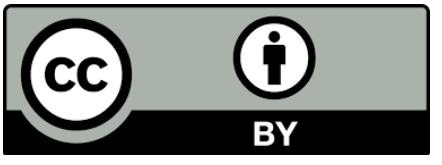

(C) 2021 by the author. This is an open access article distributed under the conditions of the Creative Commons by Attribution License, which permits unrestricted use, distribution, and reproduction in any medium or format, provided the original work is correctly cited. 
health, healing and well being. Research reveals that the public desires more access to $\mathrm{ClH}$ including palliative care settings although actual delivery of these services in health care settings remains limited. This review explores the evidence for a combined palliative care and integrative medicine approach to symptom clusters experienced by people with serious illness through increased access and funding of these services in the community and health care settings with quality practitioners.

\section{Keywords}

Integrative medicine; palliative care; symptom clusters; integrative palliative care

\section{Introduction}

Palliative care (PC) is a medical specialty that focuses on addressing symptoms in advanced, chronic and life-limiting illnesses. PC in the last months of life is referred to as hospice care. PC draws from interprofessional teamwork, communication skills that clarify a person's values and preferences, empowerment of people with serious illness to join with their clinicians and interprofessional care teams in shared decision-making, support of caregivers, and advance care planning [1]. Primary palliative care includes the palliative care skills of symptom management, advance care planning and communication that are within the clinical toolbox of all health care practitioners.

Integrative medicine (IM) broadens the interprofessional team approach to include other modalities and practitioners that are often outside of mainstream, conventional care, and referred to as complementary and integrative health $(\mathrm{ClH})$ practitioners. Examples of $\mathrm{ClH}$ therapies include supplements, acupuncture, yoga, energy healing, etc. Integrative therapies, integrative medicine and integrative practitioners combine the best of conventional medicine with evidence informed therapies outside of mainstream, conventional medicine to achieve health, wellbeing and relief of distressing physical, psychological and spiritual symptoms. Integrative medicine highlights the empowerment of people taking charge of their health, and the integration of strategies for promotion of optimal health and healing including pharmacological and non-pharmacological means, and whole person care [2]. In palliative care populations, this translates to optimal symptom management resulting in best possible function and quality of life (QOL).

Palliative care and integrative medicine/ $\mathrm{CIH}$ and their interventions are evidence-informed, and tailored to the person's goals, values and preferences [2]. Serious illness is often a strong motivator for people to reassess their health goals, and incorporate changes to their lifestyle that optimize well-being, slow the progression of disease, reduce symptom burden of the illness and treatments, and generally promote healing, meaning and purpose in living fully [3]. When a serious illness is diagnosed, people often reassess their lifestyle choices, and reach out to a variety of practitioners to support them through this illness trajectory. At this point, both integrative medicine and palliative care are appropriate and often desired to decrease fear, increase control, foster hope, and move forward in wellness through serious illness treatment and living fully[1-3]. 
Symptoms of serious, chronic illness are increasingly recognized as occurring in clusters rather than isolated symptoms treated one at a time. Integrative approaches generally address the whole person and clusters of symptoms or distress. Symptom clusters in cancer, renal disease, HIV disease, heart disease, etc, are increasingly being recognized [4]. Advanced renal disease, for example, includes the symptom cluster of fatigue, pain and depression [5]. Anticipated symptom clusters can often be treated proactively with an integrative strategy [6]. Research by Avis et al, found that high symptom burden profiles in women with breast cancer significantly decrease quality of life (QOL), and that QOL was more affected negatively with high psychological symptom burden as opposed to high pain burden [7]. Many $\mathrm{ClH}$ modalities promote emotional/psychological wellbeing while decreasing physical symptoms.

In December 2012 through March 2016, the Palliative Care Quality Network analyzed symptom assessment data from 38 inpatient palliative care teams nationally. They found that symptoms are related to others, and that the relief of one symptom is often associated with the improvement of another. Improvements in pain were correlated with relief of anxiety, nausea and dyspnea. Improving anxiety improved pain by a factor of 2.9, and dyspnea by 1.4. Comfort focused care improved pain significantly, and relief of pain, anxiety and dyspnea reduced hospital length of stay. Those with moderate to severe nausea were 3.7 times more likely to have pain as compared to patients with little to no nausea. These findings reveal that a symptom does not occur in a vacuum, but interdependent with other symptoms including their degree of severity and relief. The conventional strategy of symptom control typically addresses one symptom at a time, as though symptoms occur independently from others [8].

$\mathrm{CIH}$ modalities ideally reduce the need for medication to control symptoms. Drug side effects and drug-drug interactions can increase symptom burden. The drugs that are the most serious offenders are antiepileptics, antidepressants, corticosteroids, and opioid and nonopioid analgesics. Serious side effects such as liver and renal toxicity, sedation, delirium, etc. can occur. But less serious side effects of opioids alone can add to symptom clusters and symptom burden. Opioids can cause pruritus, nausea and vomiting, sedation, myoclonus, constipation, etc. If opioids for pain can be minimized with nonpharmacological means, the patient has improved QOL and fewer iatrogenic symptoms [9].

In this review, we will describe what are the most common complementary and integrative therapies used in PC, the common symptom clusters addressed by $\mathrm{CIH}$ therapies in PC settings, and the state of the delivery of $\mathrm{CIH}$ therapies in PC settings.

\section{Most Common ClH Therapies Used in PC}

In both PC and IM, a variety of conventional and CAM modalities can be used synergistically to avoid over-reliance on drug therapies to address symptom clusters. They also address symptoms in their complexity on all levels of wellness and distress including social, physical, emotional and spiritual aspects of whole person care. $\mathrm{CIH}$ modalities promote wellness, healing and symptom relief. Patient values and preferences must be elicited with attentive listening, presence, putting aside clinician agendas, and asking about therapies that the patient already finds essential to promoting health [10]. 


\subsection{Mindful Movement}

Many of the investigations on exercise improving symptom clusters are in advanced cancer research. Exercise improves fatigue, pain, functional capacity, mood, and QOL. Often, seriously ill patients are discouraged from movement due to concerns that movement will cause them more fatigue. Movement must be consistent with the functional capacities and desires of the person. In a review of 15 RTC's, exercise in advanced stage cancer improved QOL, fatigue, insomnia, physical function, social function and dyspnea reduction [11]. In another meta-analysis of RTC studies of people with advanced solid tumor cancers, exercise improved QOL and fatigue [12].

There is evidence for exercise and yoga improving anxiety and depression [13]. Tai Chi improves cancer related fatigue, and a reduced effect on physical and emotional fatigue. Yoga improves QOL, decreases fatigue and improves sleep in a recent Cochrane Review [14]. Qigong can improve QOL, fatigue, depression and anxiety, and reduce inflammation ( $C$ reactive protein measure) in cancer patients [15]. In people with Parkinson's Disease, a RCT of yoga versus stretching and resistance training improved anxiety and depression, and improved motor function [16].

\subsection{Supplements}

The use of nutraceuticals in the US is ubiquitous. It is estimated that 3 out of 4 adults consume supplements and botanicals [17]. In integrative palliative care (IPC), polypharmacy with nutritional supplements and pharmaceuticals at end-of-life (EOL) in particular, are ideally reduced with a careful assessment of risk/benefits of each entity, and open, nonjudgmental discussion about a person's choices, thoughts of benefit, and practitioners knowledge of potential harm or drug/drug/nutraceutical interactions. Too many supplements (or drugs) with minimal benefit can increase the burden on the patient financially and physically, and should be avoided. Each supplement and medication that is deprescribed should be fully discussed with the patient in shared decisionmaking, with the clinician being aware of the reasons why the patient has chosen to take that supplement and a fully informed discussion and education about benefits and potential harm or burden to the patient of continuing that supplement. Patients and families might hold strong beliefs about certain supplements, and those should be continued unless there is a potential harmful effect or the person is no longer able to swallow them [3]. Medications should be de-prescribed only after discussion with the primary clinician prescriber and the patient.

Vitamin D is essential for health, and a deficiency state is common in seriously ill patients who have limited sun exposure. Sources of vitamin D in food are limited. Supplementation with vitamin D3 can prevent deficiency states that could lead to fatigue, myalgias, and vague not feeling well states, increased mortality and decreased immune function [18].

Cannabis is a substance that can help with chronic pain, anxiety, appetite, depression, and fatigue. Although currently legal in 33 states and the District of Colombia, it remains a controlled substance (Schedule 1) on the federal level with no therapeutic benefits recognized [19]. Despite federal regulations, research continues on the uses of cannabis for a variety of symptoms associated with serious illness. In 2017, the National Academy of Sciences, Engineering and Medicine published a report 
on the evidence supporting the use of cannabis in medicine. The reviewers found strong evidence for the use of cannabis for chronic pain, patient reported muscle spasticity in multiple sclerosis (MS), and chemotherapy induced nausea and vomiting. Limited evidence exists for improvement of insomnia due to sleep apnea, fibromyalgia, chronic pain and MS. There was insufficient evidence to support cannabis use for cancer related cachexia and anorexia [20]. Karim et al found that authorizations for cannabis use in Canada between 2014 and 2016 in people with a cancer diagnosis were associated with younger age, active cancer treatment and more serious illness[21].

The cannabis plant has more than 100 different components, including cannabinoids, flavonoids and terpinoids, with delta-9-THC being the most psychoactive component. Cannabidiol (CBD) also has powerful therapeutic effects, but without psychoactive side effects, and can help modulate and enhance the central nervous system effects of THC (called the "Entourage Effect") [22]. Cannabinoid receptors are located in the central and peripheral nervous system (CB1) and the immune system (CB2) [23]. A great deal more research is needed to understand the full breadth and applications for this plant and its components in improving well-being [22].

Medical cannabis has a potential role in PC for the relief of anorexia, pain, nausea, insomnia, depression, pain, and anxiety according to Abrams and Guzman. Oral forms are longer acting but have variable bioavailability in the Gl tract. Inhaled or vaporized forms are shorter acting, and more immediate in effect. The cytochrome P450 enzymes in the liver are affected by cannabis, which can affect the metabolism of other drugs [24].

In a review of 165 studies on medical marijuana use, less than $7 \mathrm{mg}$ of THC is considered as low dose, 7-18 $\mathrm{mg}$ as medium dose, and greater than $18 \mathrm{mg}$ as high dose. Tolerance occurs generally in a few days through downregulation of cannabis receptors [25]. Most side effects of cannabis are due to THC and include dizziness, dry mouth, sedation, fatigue, headache, hypotension, irritability, and poor memory or concentration. More serious side effects include paranoia, psychosis, and disorientation [26]. Psychoactive side effects can worsen mental illness, psychotic illness, dementia, or delirium. Addiction potential is much less than alcohol, opioids and other drugs of addiction, but higher in heavy chronic users and adolescents. Cannabis intoxication can cause transient psychosis. Cannabinoids can inhibit hepatic enzymes and interfere with drug concentrations of antiviral medications and warfarin $[20,27]$.

\subsection{Mind-Body Therapies}

Because each individual experiences symptoms uniquely, it is useful to utilize a variety of different mind-body therapies to address chronic pain, fatigue, anxiety, depression and insomnia. These symptoms, which typically occur in clusters, are experienced on a subjective level, and therefore using techniques that help to alter the way in which the symptoms are experienced can assist in the decreasing that symptom or cluster of symptoms. For example, physical pain is modulated by the mind in perceiving and interpreting the stimulus of symptoms such as pain (in chronic pain, stimulus is no longer able to be identified) [28]. Mind body therapies work on chronic pain by activating modulating areas of the brain, decrease sympathetic nervous system (SNS) activation, activates the 
parasympathetic nervous system (PNS), and hormones released, and regenerates neuronal tissue. By activating the PNS and decreasing SNS, anxiety and stress are decreased as well [29].

\subsection{Mindfulness-Based Stress Reduction}

Mindfulness-based stress reduction (MBSR), developed by Jon Kabat-Zinn and having its basis in vipassana meditation, incorporates several modalities that can be used with PC patients. These include walking, sitting, or lying meditation, body scan meditation, gentle movement and Hatha yoga, and breath awareness [30]. MBSR is typically taught in an eight-week program and a meta-analytic review of MBSR found that participants who completed this program experienced reductions in chronic pain, depression, anxiety and stress. These types of symptoms are often experienced by patients facing serious disease or at the end of life [31,32]. Using the techniques of MBSR can also increase calmness and peace, quality of life, and well-being [22,33]. Even a single class in MBSR was found by one study to increase well-being and reduce symptoms of anxiety, fatigue and dyspnea. (38) One large metaanalysis from Boston University [33] found that mindfulness had a moderate effect size in improving anxiety and depressive symptoms. For patients with both anxiety and mood issues, mindfulness training had a larger effect size. These changes were robust and maintained over time. Another metaanalysis showed improvements in depression, anxiety, and pain from mindfulness [34].

Mindfulness has also been effective in addressing the psychological stressors and coping with chronic and life-threatening illnesses [35]. In cancer patients, studies have shown mindfulness is associated with improvements in mood and a reduction of stress [36] and improvements in quality of life [37]. Research also supports mindfulness for coping with rheumatoid arthritis, cardiovascular disease, diabetes, HIV/AIDs, irritable bowel syndrome, organ transplant, chronic pain, and fibromyalgia [35].

\subsection{Hypnosis and Guided Imagery}

Similar to MBSR, hypnosis and guided imagery can help to reduce pain, stress and anxiety. They can also help to attenuate nausea and vomiting in patients undergoing chemotherapy. (41) A study of clinical and self-hypnosis found that PC patients receiving hypnosis as an adjuvant therapy experienced significantly less anxiety and pain and received less pain medications up to two years after the intervention. The control group were 4 times more likely to need an escalation in analgesic medication [38]. Hypnosis promotes relaxation and helps to focus attention, which has been shown to improve well-being and resilience when facing death [39, 40]. It was found that nurse led guided imagery in an inpatient PC unit, decreased pain, heart rate, respiratory rate and increased comfort for patients [41].

\subsection{Music Therapy}

Music therapy consists of many therapeutic approaches that range from listening to music that a person finds enjoyable, relaxing and uplifting or music that is created or played for a therapeutic purpose generally delivered by a music therapist. The former intention of this modality is passive, and the latter form is more active and prescriptive. In a meta-analysis and systematic review of music 
therapy in terminally ill patients, Yinyan et al. found that this $\mathrm{ClH}$ modality significantly reduced anxiety, depression, pain and insomnia, and improved mood and QOL. It did not seem to have an effect on fatigue [42]. Gao et al. also performed a similar analysis of 11 RCT's and found that music therapy significantly reduced pain, anxiety, depression, and improved emotional function and QOL [42]. The duration of the music therapy does not have to be long, and in a review of 18 RCT's in ICU's, music therapy for 20-30 minutes reduced pain scores by about 1.06 on a 10 point scale [43]. In another study, prescribed music sessions for 30 minutes five times a week compared to ambient music relieved pain and fatigue $[44,45]$. Harp music therapy in one study relieved anxiety, fear, dyspnea, nausea, and pain, and helped $77 \%$ of patients [46]. Music therapy can help relieve depression, and in one study reduced pain intensity by $70 \%$, and decreased opioid requirements $[47,48]$.

\subsection{Massage}

Many forms of massage therapy can have a therapeutic effect on symptom clusters. Multiple studies have shown efficacy for relief of pain, anxiety, depression, and insomnia [49-58]. In a large study of cancer patients, massage relieved pain, fatigue, anxiety and nausea by $50 \%[59,60]$. Hand massage can help with dementia related agitation by promoting relaxation [61]. Massage therapy is offered frequently in hospice settings due to benefits of touch, and relaxation[62-64].

\subsection{Aromatherapy}

Aromatherapy is often combined with massage therapy, but can also be used alone in a diffuser or on a cotton ball attached to the patient's garments. Small studies that used aromatherapy alone found that lavender can help decrease anxiety, rosemary oil can increase alertness and reduce anxiety, and spearmint and peppermint oils can help relieve nausea due to chemotherapy [65-67]. In a systematic review of aromatherapy, massage and reflexology studies, these modalities were reported as frequently used in PC and hospice settings, but with limited quality evidence for positive outcomes[68]. In another systematic review, aromatherapy massage showed benefit for psychological well-being and anxiety. Limited evidence existed for benefits in nausea, pain, and depression [69].

\subsection{Healing Touch, Therapeutic Touch and Reiki Therapy}

Reiki, healing touch and therapeutic touch are considered biofield therapies. Healing touch and therapeutic touch include a focus on the part of the practitioner to heal the patient through a transfer of energy from the environment, through the practitioner to the patient without actually touching the patient. In a systematic review and a study of hospital in patients, these healing modalities reduced pain, anxiety and increased relaxation [70-72]. Reiki therapy balances energy fields of the patient. Here a light touch is often used. Reiki may reduce pain and anxiety [73]. In one review of biofield therapies, Hanneghan and Schnyder found that these therapies can relieve pain, improve QOL and wellbeing, and redure stress [70]. Results of another study were inconclusive [74]. 


\subsection{Acupuncture and Traditional Chinese Medicine}

Acupuncture is a complex $\mathrm{ClH}$ modality that addresses the whole person and not just a specific symptom. This is one reason acupuncture is an ideal modality to treat symptom clusters. Evidence shows that it can effectively treat nausea, pain (both nociceptive and neuropathic), anxiety, fatigue, and increase well being. Other studies also shows a positive effect on insomnia, depression, vasomotor instability, and xerostomia [75-82]. At a National Cancer Institute's conference on acupuncture, this modality was found to be safe and effective. They expressed caution with acupuncture for those patients who are neutropenic, and thrombocytopenic. In a meta-analysis of 20 RCT's of acupuncture in oncology patients, they found that acupuncture combined with analgesics provided faster pain relief with improved QOL [83].

\section{Delivery of CIH Therapies in PC Settings}

$\mathrm{ClH}$ use in hospice and palliative care settings is popular, yet accessibility of these services is challenging. For profit hospices in a survey of hospices in Texas were 4 times less likely to offer $\mathrm{ClH}$ services [84]. Larger hospices and non-profit hospices located in the Northwest regions of the US were more likely to employ a $\mathrm{ClH}$ practitioner [85]. Kozak et al. found that $86 \%$ of hospices in Washington state offered $\mathrm{CIH}$ therapies, but practitioners were largely volunteer and $\mathrm{ClH}$ services were not covered by the Medicare hospice benefit [63]. In a Nevada and Montana hospice survey of $\mathrm{ClH}$ services, $70 \%$ of hospices provided these services, but less than $25 \%$ of patients received them [86]. In another hospice survey, $60 \%$ of these hospices provided $\mathrm{ClH}$ services, but less than $25 \%$ of patients received them [62]. A national survey of hospices funded by US Department of Human Services, the Center for Disease Control and National Center for Health Statistics found that $42 \%$ of hospices offered CIH services [64]. In another national survey of hospices in the US, 29\% employed a $\mathrm{CHI}$ therapist, which included a massage therapist $74 \%$ of the time, $53 \%$ music and $22 \%$ art [85].

$\mathrm{ClH}$ therapies are commonly used by oncology patients for symptom control, well-being and healing. From 1997 to 2005, Sirios notes that motivation to seek $\mathrm{ClH}$ therapies changed from predominantly using them as an alternative to conventional care, to a more empowered, positive integrative approach using $\mathrm{ClH}$ therapies to augment conventional therapies. (97) In a Swedish study of cancer patients, 26\% reported use of $\mathrm{ClH}$ therapies to optimize health, fight disease, and increase physical and emotional wellbeing [87]. In many surveys, satisfaction with $\mathrm{ClH}$ is high, and satisfaction with hospice services is increased with $\mathrm{ClH}$ use $[87,88]$. Barriers identified that negatively impact patient disclosure of $\mathrm{ClH}$ use to oncologists include: physician did not ask or that they felt their physician did not want to know. In one study, only $26 \%$ of patients disclosed $\mathrm{ClH}$ use to their oncologists $[87,89]$. Barriers to $\mathrm{ClH}$ use in hospices include lack of funding/reimbursement, lack of $\mathrm{ClH}$ providers, resistance to $\mathrm{ClH}$ modalities by staff and patients, and lack of knowledge about benefits of $\mathrm{ClH}$ [62].

The most common $\mathrm{ClH}$ modalities offered by hospices include massage therapy, music therapy, pet therapy, guided imagery, reiki, aromatherapy, harp music, reflexology, hypnosis, acupuncture and art therapy. Less offered modalities included movement therapies [62-64]. In oncology patients, supplements and osteopathic and chiropractic manipulation use was $36 \%$ and $25 \%$ respectively, with 
less frequent use of massage, movement therapies, and mindfulness meditation [89]. In a Canadian PC unit study, $\mathrm{ClH}$ modalities contributed to a decrease in intensity of pain, restlessness, low mood, and anxiety and increased a sense of peace [90]. $\mathrm{ClH}$ are considered generally safe, well tolerated. In their systematic review of CAM in hospice and palliative care, Zeng et al. discovered many barriers to research of $\mathrm{ClH}$ in this population, but also found that reike, music and massage therapy had the highest potential benefits [91].

\section{Discussion}

The skills required to provide integrative palliative care are not currently taught in most health science professional training programs, but many of the core concepts and skill set taught in PC are in alignment with $\mathrm{CIH}$ care. As we have addressed above, $\mathrm{CIH}$ modalities are a valuable resource to address symptom clusters in palliative care patients. IPC calls on us to be creative and innovative in the care of seriously ill patients, expanding options to enhance healing, maintain hope, and improve wellbeing in a unique way for each person

PC can occur together with life-prolonging measures, and with the relief of symptoms and improvements in quality of life (QOL), PC may actually prolong life [1].

Pharmaceuticals are widely available for symptom cluster management, but with significant side effects and risk of harm[9]. They seldom treat the root cause of symptoms, and provide limited symptom relief. Pharmaceuticals can be effective, but $\mathrm{ClH}$ modalities allow for the possibility of reducing the need for medications with challenging and harmful side effects, and increase wellbeing, healing and health in serious illness and at end of life [9]. Optimally, medications are used safely, monitored closely and used in the lowest effective dose. Nutriceutical and drug interactions are largely underappreciated, since conventional practitioners rarely ask their patients about their use, or without knowledgeable about supplements, dismiss them and discourage their use [89].

$\mathrm{CIH}$ continues to be available to people primarily in outpatient settings, and is an out of pocket expense limiting access unless services are affordable. Inpatient PC settings at times provide services such as music, art, limited massage and aromatherapy and pet therapy to patients [3]. Less available are acupuncture, biofield therapies and narrative interventions. Although cancer centers and hospices generally offer a wide array of $\mathrm{ClH}$ services, hospital-basedPC settings may have a limited number of practitioners trained in $\mathrm{ClH}$, despite high patient satisfaction with $\mathrm{ClH}$ modalities for overall comfort and wellness.

Few hospital-based PC practitioners ask their patients about $\mathrm{ClH}$ therapies, and few prescribe them or are knowledgeable about these therapies. Within hospices, $\mathrm{CIH}$ therapies and practitioners are generally underfunded, and facilities rely on volunteer services [63, 92].

Studies of IPC are often in PC inpatient units, hospices or oncology populations. There is a need for more study of symptom clusters across all advanced serious illnesses and the symptom clusters they produce and the therapies that are most effective in relieving them. In PC populations, patient often have more than one serious illness, therefore evidence based on a single disease entity in PC studies is challenging. 


\section{Conclusions}

Surveys of people enduring serious illness reveal the use and significance of $\mathrm{ClH}$ in an overall strategy to reduce drug side effects, and support health and wellness [3, 9]. An integrative approach to palliative care allows for healing modalities that support overall wellness and reduce suffering from physical, emotional, and spiritual distress. Addressing palliative care symptoms from the perspective of symptom clusters allows for a more wholistic approach to $\mathrm{PC}$. $\mathrm{ClH}$ modalities are important and effective in treating symptom clusters and there is a need to prioritize access to these modalities with well-trained clinicians from both, the conventional and $\mathrm{ClH}$ fields.

\section{Acknowledgements}

Thank you to Emily Patridge, MLS, for her significant contributions to the researching of this document. Emily Patridge is the librarian of the Osher Center for Integrative Medicine at the University of WA, Seattle.

\section{Author Contributions}

LM: Most (80\%) of the writing, editing, research, submission of manuscript. DL: Writing, Editing, research. LK: Writing, editing, research.

\section{Competing interests}

The authors have declared that no competing interests exist.

\section{References}

1. Marchand L. Integrative and complementary therapies for patients with advanced cancer. Ann Palliat Med. 2014; 3: 160-171.

2. Adler SR, Marchand LR, Heap N. Integrative palliative care: Enhancing the natural synergy between integrative health and palliative medicine. J Altern Complement Med. 2019; 25:257-259.

3. Marchand L. Palliative and end of life care. In Integrative Medicine. Amsterdam: Elsevier Health Sciences; 2017.

4. Zhu Z, Hu Y, Xing W, Guo M, Zhao R, Han S, et al. Identifying symptom clusters among people living with HIV on antiretroviral therapy in China: A network analysis. J Pain Symptom Manage. 2019; 57 : 617-626.

5. Jhamb M, Abdel-Kader K, Yabes J, Wang Y, Weisbord SD, Unruh M, et al. Comparison of fatigue, pain, and depression in patients with advanced kidney disease and cancer-symptom burden and clusters. J Pain Symptom Manage. 2019; 57: 566-575.e3.

6. Hsu HT, Lin KC, Wu LM, Juan CH, Hou MF, Hwang SL, et al. Symptom cluster trajectories during chemotherapy in breast cancer outpatients. J Pain Symptom Manage. 2017; 53: 1017-1025.

7. Avis NE, Levine $B$, Marshall SA, Ip EH. Longitudinal examination of symptom profiles among breast cancer survivors. J Pain Symptom Manage. 2017; 53: 703-710. 
8. Bischoff KE, O'Riordan DL, Fazzalaro K, Kinderman A, Pantilat SZ. Identifying opportunities to improve pain among patients with serious illness. J Pain Symptom Manage, 2018; 55: 881-889.

9. Kotlinska-Lemieszek A, Klepstad P, Haugen DF. Clinically significant drug-drug interactions involving medications used for symptom control in patients with advanced malignant disease: A systematic review. J Pain Symptom Manage. 2019; 57: 989-998.e1.

10. Skarf LM, Stowers KH, Thurston A. Essentials 5: Communication and teamwork. In Essential Practices in Hospice and Palliative Medicine. 5th ed. Chicago, IL: American Academy of Hospice and Palliative Medicine; 2017.

11. Chen YJ, Li XX, Ma HK, Zhang X, Wang BW, Guo TT, et al. Exercise training for improving patientreported outcomes in patients with advanced-stage cancer: A systematic review and meta-analysis. J Pain Symptom Manage. 2020; 59: 734-749.e10.

12. Nadler MB, Desnoyers A, Langelier DM, Amir E. The effect of exercise on quality of life, fatigue, physical function, and safety in advanced solid tumor cancers: A meta-analysis of randomized control trials. J Pain Symptom Manage. 2019; 58: 899-908.e7.

13. Saeed SA, Cunningham K, Bloch RM. Depression and anxiety disorders: Benefits of exercise, yoga, and meditation. Am Fam Physician. 2019; 99: 620-627.

14. Cramer H, Lauche R, Klose P, Lange S, Langhorst J, Dobos GJ. Yoga for improving health-related quality of life, mental health and cancer-related symptoms in women diagnosed with breast cancer. Cochrane Database Syst Rev. 2017: CD010802.

15. Oh B, Butow P, Mullan B, Clarke S, Beale P, Pavlakis N, et al. Impact of medical Qigong on quality of life, fatigue, mood and inflammation in cancer patients: A randomized controlled trial. Ann Oncol. 2010; 21: 608-614.

16. Kwok JY, Kwan JC, Auyeung M, Mok VC, Lau CK, Choi KC, et al. Effects of mindfulness yoga vs stretching and resistance training exercises on anxiety and depression for people with Parkinson disease: A randomized clinical trial. JAMA Neurol. 2019; 76: 755-763.

17. Sancar F. Oversight of supplements. JAMA. 2019; 321: 1042.

18. Björkhem-Bergman L, Bergman P. Vitamin D and patients with palliative cancer. BMJ Support Palliat Care. 2016; 6: 287-291.

19. State marijuana laws - U.S. map [Internet]. Folsom, CA: Govering. Available from: https://www.governing.com/gov-data/safety-justice/state-marijuana-laws-map-medicalrecreational.html.

20. Wells J. Dazed and confused: Marijuana legalization raises the need for more research. San Francisco, CA: UCSF Magazine; 2017. Available from: https://www.ucsf.edu/news/2017/06/407351/dazed-and-confused-marijuana-legalizationraises-need-more-research.

21. Karim S, Cheung WY, Bu J, Jess E, Kerba M. Medical cannabis authorization in patients with cancer in the prelegalization era: A population-based study. J Pain Symptom Manage. 2020; 59: 1223-1231.

22. Baron EP. Comprehensive review of medicinal marijuana, cannabinoids, and therapeutic implications in medicine and headache: What a long strange trip it's been.... Headache. 2015; 55: 885-916. 
23. Walsh D, Nelson KA, Mahmoud F. Established and potential therapeutic applications of cannabinoids in oncology. Support Care Cancer. 2003; 11: 137-143.

24. Abrams DI, Guzman M. Cannabis in cancer care. Clin Pharmacol Ther. 2015; 97: 575-586.

25. Zuurman L, Ippel AE, Moin E, Van Gerven JM. Biomarkers for the effects of cannabis and THC in healthy volunteers. Br J Clin Pharmacol. 2009; 67: 5-21.

26. Borgelt LM, Franson KL, Nussbaum AM, Wang GS. The pharmacologic and clinical effects of medical cannabis. Pharmacotherapy. 2013; 33: 195-209.

27. Wilkinson ST, Yarnell S, Radhakrishnan R, Ball SA, D'Souza DC. Marijuana iegalization: Impact on physicians and public health. Annu Rev Med. 2016; 67: 453-466.

28. Harris RE. Central pain states: A shift in thinking about chronic pain. In Integrative Pain Management. Oxford, UK: Oxford University Press; 2016.

29. Del Casale A, Ferracuti S, Rapinesi C, Serata D, Caltagirone SS, Savoja V, et al. Pain perception and hypnosis: Findings from recent functional neuroimaging studies. Int J Clin Exp Hypn. 2015; 63: 144170.

30. Monti DA, Yang J. Complementary medicine in chronic cancer care. Semin Oncol. 2005; 32: 225231.

31. Grossman P, Niemann L, Schmidt S, Walach H. Mindfulness-based stress reduction and health benefits: A meta-analysis. J Psychosom Res. 2004; 57: 35-43.

32. Kabat-Zinn J, Lipworth L, Burney R. The clinical use of mindfulness meditation for the selfregulation of chronic pain. J Behav Med. 1985; 8: 163-190.

33. Hoffman CJ, Ersser SJ, Hopkinson JB, Nicholls PG, Harrington JE, Thomas PW. Effectiveness of mindfulness-based stress reduction in mood, breast-and endocrine-related quality of life, and wellbeing in stage 0 to III breast cancer: A randomized, controlled trial. J Clin Oncol. 2012; 30: 13351342.

34. Goyal M, Singh S, Sibinga EM, Gould NF, Rowland-Seymour A, Sharma R, et al. Meditation programs for psychological stress and well-being: A systematic review and meta-analysis. JAMA Intern Med. 2014; 174: 357-368.

35. Carlson LE. Mindfulness-based interventions for physical conditions: A narrative review evaluating levels of evidence. Int Sch Res Not. 2012; 2012. 651583.

36. Speca M, Carlson LE, Goodey E, Angen M. A randomized, wait-list controlled clinical trial: The effect of a mindfulness meditation-based stress reduction program on mood and symptoms of stress in cancer outpatients. Psychosom Med. 2000; 62: 613-622.

37. Lerman R, Jarski R, Rea H, Gellish R, Vicini F. Improving symptoms and quality of life of female cancer survivors: A randomized controlled study. Ann Surg Oncol. 2012; 19: 373-378.

38. Brugnoli MP, Pesce G, Pasin E, Basile MF, Tamburin S, Polati E. The role of clinical hypnosis and selfhypnosis to relief pain and anxiety in severe chronic diseases in palliative care: A 2-year long-term follow-up of treatment in a nonrandomized clinical trial. Ann Palliat Med. 2018; 7: 17-31.

39. Trueman I. Life review: An educational perspective. In Delivering cancer and palliative care education. England: Radcliffe Publishing; 2004.

40. Facco E, Casiglia E, Zanette G, Testoni I. On the way of liberation from suffering and pain: Role of hypnosis in palliative care. Ann Palliat Med. 2018; 7: 63-74. 
41. Coelho A, Parola V, Sandgren A, Fernandes O, Kolcaba K, Apóstolo J. The effects of guided imagery on comfort in palliative care. J Hosp Palliat Nurs. 2018; 20: 392-399.

42. Gao Y, Wei Y, Yang W, Jiang L, Li X, Ding J, et al. The effectiveness of music therapy for terminally ill patients: A meta-analysis and systematic review. J Pain Symptom Manage. 2019; 57: 319-329.

43. Richard-Lalonde M, Gélinas C, Boitor M, Gosselin E, Feeley N, Cossette S, et al. The effect of music on pain in the adult intensive care unit: A systematic review of randomized controlled trials. J Pain Symptom Manage. 2020; 59: 1304-1319.e6.

44. Hsieh FC, Miao NF, Tseng IJ, Chiu HL, Kao CC, Liu D, et al. Effect of home-based music intervention versus ambient music on breast cancer survivors in the community: A feasibility study in Taiwan. Eur J Cancer Care. 2019; 28: e13064.

45. Schmid W, Rosland JH, von Hofacker S, Hunskår I, Bruvik F. Patient's and health care provider's perspectives on music therapy in palliative care-an integrative review. BMC Palliat Care. 2018; 17: 32.

46. Lewis CR, de Vedia A, Reuer B, Schwan R, Tourin C. Integrating complementary and alternative Medicine (CAM) into standard hospice and palliative care. Am J Hosp Palliat Care. 2003; 20: 221228.

47. Maratos A, Gold C, Wang X, Crawford M. Music therapy for depression. Cochrane Database Syst Rev. 2008: CD004517.

48. Carr DB, Lau J, Alvarez H. Music for pain relief. Cochrane Database Syst Rev. 2006: CD004843.

49. Field TM. Massage therapy effects. Am Psychol. 1998; 53: 1270-1281.

50. Field T. Massage therapy. Med Clin. 2002; 86: 163-171.

51. Hurley D. Massage is better than acupuncture (and in the short term better than self-care) in reducing pain and disability in patients with chronic low back pain. Aust J Physiother. 2001; 47: 299.

52. Cherkin DC, Eisenberg D, Sherman KJ, Barlow W, Kaptchuk TJ, Street J, et al. Randomized trial comparing traditional Chinese medical acupuncture, therapeutic massage, and self-care education for chronic low back pain. Arch Intern Med. 2001; 161: 1081-1088.

53. Ernst E. Massage therapy for low back pain: A systematic review. J Pain Symptom Manage. 1999; 17: 65-69.

54. Wright A, Sluka KA. Nonpharmacological treatments for musculoskeletal pain. Clin J Pain. 2001; 17: 33-46.

55. Hernandez-Reif M, Ironson G, Field T, Hurley J, Katz G, Diego M, et al. Breast cancer patients have improved immune and neuroendocrine functions following massage therapy. J Psychosom Res. 2004; 57: 45-52.

56. Post-White J, Kinney ME, Savik K, Gau JB, Wilcox C, Lerner I. Therapeutic massage and healing touch improve symptoms in cancer. Integr Cancer Ther. 2003; 2:332-344.

57. Smith MC, Kemp J, Hemphill L, Vojir CP. Outcomes of therapeutic massage for hospitalized cancer patients. J Nurs Scholarsh. 2002; 34: 257-262.

58. Soden K, Vincent K, Craske S, Lucas C, Ashley S. A randomized controlled trial of aromatherapy massage in a hospice setting. Palliat Med. 2004; 18: 87-92.

59. Cassileth BR, Vickers AJ. Massage therapy for symptom control: outcome study at a major cancer center. J Pain Symptom Manage. 2004; 28: 244-249. 
60. Kozak L, Vig E, Simons C, Eugenio E, Collinge W, Chapko M. A feasibility study of caregiver-provided massage as supportive care for veterans with cancer. J Support Oncol. 2013; 11: 133-143.

61. Hansen NV, Jørgensen T, Ørtenblad L. Massage and touch for dementia. Cochrane Database Syst Rev. 2006: CD007502.

62. Demmer C. A survey of complementary therapy services provided by hospices. J Palliat Med. 2004; 7: 510-516.

63. Kozak LE, Kayes L, McCarty R, Walkinshaw C, Congdon S, Kleinberger J, et al. Use of complementary and alternative medicine (CAM) by Washington State hospices. Am J Hosp Palliat Care. 2009; 25: 463-468.

64. Bercovitz A, Harris-Kojetin LD, Jones A, Sengupta M. Complementary and alternative therapies in hospice: The national home and hospice care survey: United States, 2007. In Natl Health Statistics Reports. Hyattsville, MD: National Center for Health Statistics; 2010.

65. Diego MA, Jones NA, Field T, Hernandez-Reif M, Schanberg S, Kuhn C, et al. Aromatherapy positively affects mood, EEG patterns of alertness and math computations. Int J Neurosci. 1998; 96: 217-224.

66. Dunn C, Sleep J, Collett D. Sensing an improvement: An experimental study to evaluate the use of aromatherapy, massage and periods of rest in an intensive care unit. J Adv Nurs. 1995; 21: 34-40.

67. Tayarani-Najaran Z, Talasaz-Firoozi E, Nasiri R, Jalali N, Hassanzadeh MK. Antiemetic activity of volatile oil from mentha spicata and mentha $\times$ piperita in chemotherapy-induced nausea and vomiting. Ecancermedicalscience. 2013; 7: 290.

68. Candy B, Armstrong M, Flemming K, Kupeli N, Stone P, Vickerstaff V, et al. The effectiveness of aromatherapy, massage and reflexology in people with palliative care needs: A systematic review. Palliat Med. 2020; 34: 179-194.

69. Fellowes D, Barnes K, Wilkinson SS. Aromatherapy and massage for symptom relief in patients with cancer. Cochrane Database Syst Rev. 2004: CD002287.

70. Henneghan AM, Schnyer RN. Biofield therapies for symptom management in palliative and end-oflife care. Am J Hosp Palliat Care. 2015; 32: 90-100.

71. Olson M, Sneed N. Anxiety and therapeutic touch. Issues Ment Health Nurs. 1995; 16: 97-108.

72. Newshan G, Schuller-Civitella D. Large clinical study shows value of therapeutic touch program. Holist Nurs Pract. 2003; 17: 189-192.

73. Wardell DW, Weymouth KF. Review of studies of healing touch. J Nurs Scholarsh. 2004; 36: 147154.

74. Miles P, True G. Reiki-review of a biofield therapy: History, theory, practice, and research. Altern Ther Health Med. 2003; 9: 62-72.

75. Alimi D, Rubino C, Pichard-Léandri E, Fermand-Brulé S, Dubreuil-Lemaire ML, Hill C. Analgesic effect of auricular acupuncture for cancer pain: A randomized, blinded, controlled trial. J Clin Oncol. 2003; 21: 4120-4126.

76. Dalamagka M. Systematic review: Acupuncture in chronic pain, low back pain and migraine. J Pain Relief. 2015; 4: 195. 
77. Tick H, Nielsen A, Pelletier KR, Bonakdar R, Simmons S, Glick R, et al. Evidence-based nonpharmacologic strategies for comprehensive pain care: The consortium pain task force white paper. Explore. 2018; 14: 177-211.

78. Wu X, Chung VC, Hui EP, Ziea ET, Ng BF, Ho RS, et al. Effectiveness of acupuncture and related therapies for palliative care of cancer: Overview of systematic reviews. Sci Rep. 2015; 5: 16776.

79. Lau CH, Wu X, Chung VC, Liu X, Hui EP, Cramer H, et al. Acupuncture and related therapies for symptom management in palliative cancer care: Systematic review and meta-analysis. Medicine. 2016; 95: e2901.

80. Miller KR, Patel JN, Symanowski JT, Edelen CA, Walsh D. Acupuncture for cancer pain and symptom management in a palliative medicine clinic. Am J Hosp Palliat Care. 2019; 36: 326-332.

81. von Trott $P$, Oei SL, Ramsenthaler C. Acupuncture for breathlessness in advanced diseases: $A$ systematic review and meta-analysis. J Pain Symptom Manage. 2020; 59: 327-338.e3.

82. Ahn AC. Acupuncture [Internet]. UpToDate; 2020. Available from: https://www.uptodate.com/contents/acupuncture.

83. Zia FZ, Olaku O, Bao T, Berger A, Deng G, Yin Fan A, et al. The national cancer institute's conference on acupuncture for symptom management in oncology: State of the science, evidence, and research gaps. J Natl Cancer Inst Monogr. 2017; 2017: Igx005.

84. Olotu BS, Brown CM, Lawson KA, Barner JC. Complementary and alternative medicine utilization in Texas hospices: Prevalence, importance, and challenges. Am J Hosp Palliat Care. 2014; 31: 254-259.

85. Dain AS, Bradley EH, Hurzeler R, Aldridge MD. Massage, music, and art therapy in hospice: Results of a national survey. J Pain Symptom Manage. 2015; 49: 1035-1041.

86. Running A, Shreffler-Grant J, Andrews W. A survey of hospices use of complementary therapy. J Hosp Palliat Nurs. 2008; 10: 304-312.

87. Wode K, Henriksson R, Sharp L, Stoltenberg A, Nordberg JH. Cancer patients' use of complementary and alternative medicine in Sweden: A cross-sectional study. BMC Complement Altern Med. 2019; 19: 62.

88. Demmer C, Sauer J. Assessing complementary therapy services in a hospice program. Am J Hosp Palliat Care. 2002; 19: 306-314.

89. Sanford NN, Sher DJ, Ahn C, Aizer AA, Mahal BA. Prevalence and nondisclosure of complementary and alternative medicine use in patients with cancer and cancer survivors in the United States. JAMA Oncol. 2019; 5: 735-737.

90. Berger $L$, Tavares $M$, Berger B. A Canadian experience of integrating complementary therapy in a hospital palliative care unit. J Palliat Med. 2013; 16: 1294-1298.

91. Zeng YS, Wang C, Ward KE, Hume AL. Complementary and alternative medicine in hospice and palliative care: A systematic review. J Pain Symptom Manage. 2018; 56: 781-794.e4.

92. Van Hyfte GJ, Kozak LE, Lepore M. A survey of the use of complementary and alternative medicine in Illinois hospice and palliative care organizations. Am J Hosp Palliat Care. 2014; 31: 553-561. 
OBM Integrative and Complementary Medicine 2021; 6(1), doi:10.21926/obm.icm.2101007

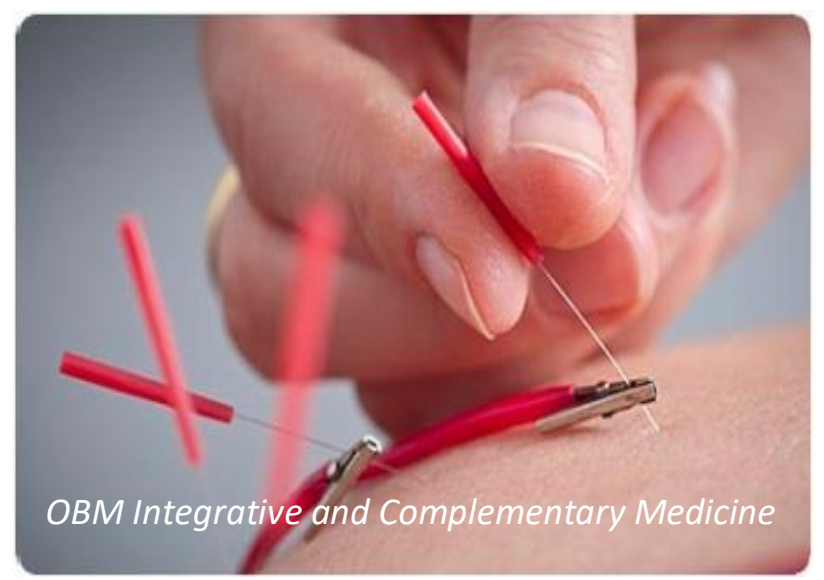

Enjoy $O B M$ Integrative and Complementary Medicine by:

1. Submitting a manuscript

2. Joining in volunteer reviewer bank

3. Joining Editorial Board

4. Guest editing a special issue

For more details, please visit:

http://www.lidsen.com/journals/icm 